\title{
Research on the Return of Public Interests from the Perspective of Power Game between Government and Market
}

\author{
Xiaotao Guo \\ Music College, Minzu University of China, Beijing, 100081, China
}

Keywords: Government and market, Public interests, Power game

\begin{abstract}
With the development of society, our government and market are playing games and promoting each other in the process of perfection. The game between the government and the market has never stopped. The change of the times makes it difficult to identify the affiliation relationship between the government and the market for public management interests. It is particularly important to understand the main impact of the return of public interests through the power game between the government and the market. In the life, power game between the government and the market get too much attention, which will lead to the deviation of understanding of the real meaning of public management to a certain extent, forming the paradox in public administration slowly. Through the analysis of the existing problems in the current power game between government and market, the purpose of this paper is to help the government and the market to promote each other in the future and contribute to the development of our country.
\end{abstract}

\section{Power Game between Government and Market in Public Interests}

\subsection{Reasons for Power Game}

In the long river of historical development, since the emergence of the capitalist society, the status of the government in the society has gradually been influenced by the capitalist social phenomenon. The government and the market have become the two main bodies of public management. The cause of this phenomenon is due to the influence of western culture. Under the influence of western traditional culture, people often think that the government's rights are "evil", and that the symbol of government rights is to realize the increase of public interest. Only through the increase of public interest, the government can get legal existence. It is called the "necessary evil" by some. This phenomenon leads to the limitation of the government's public management rights in the scope of the western countries. In some other things, the rights of the government are not obvious. The government's rights are mainly reflected in the maintenance of the security of the state, the public security, and so on. In the period of that time the government was also called the government. "The night watchman government", and the value of the market in the western countries, the value of the existence of the increase, the main management in the society depends on the market, some western people call the market "market myth." After analysis and understanding of the cause of the economic crisis, Marshall and other well-known scholars proposed to increase the public management ability of the government to improve social phenomena and reduce the loss caused by the economic crisis. Since then, the game between the government and the market has always existed in the society and has never stopped.

\subsection{Process of Power Game}

At the end of the 1920s and early 1930s of the capitalist society, many public goods were destroyed by the capitalist, and the living standard of the people was getting lower and lower, which led to a reduction of about $1 / 3$ of the economic value of some countries. But the regulation of the law of value has not been restored to the original value model, and the market is slowly losing the right of public management in this change, because in the face of the problem, the market cannot effectively 
regulate the public management, and when problems arise, it cannot be properly handled and solved. At that time, Keynes, a famous economist, published books about market and government, called employment, interest and currency. This book is mainly an analysis of the responsibility of the government and the public management of the market. He believes that the government should appropriately increase the rights of the public management to better make up the shortage of the market in dealing with the problems, to be more specialized in the management of the society, and to reduce the loss of public goods and public interests. Since then, the government has more and more rights in the public management, and some enterprises are also taken into the state, the government is very comprehensive in the management of the society. At the same time, this period is also known as the "golden period" of the development of capitalism. However, with the progress of the times, the government has shown a less optimistic direction in the face of public administration, and the rights of the government are too expansive so that the western countries have entered the "stagflation period" from the "golden period" of the time. So, for the emergence of this imagination, some people attribute their responsibility to the "Keynes doctrine". They think that the thought of the country that Keynes advocates should strengthen the right of public management to cause the present bad situation. Therefore, from the historical point of view, the relationship between the public interest of the government and the public management between the government and the market will be better to promote the coordinated development of the government and the market.

\subsection{Results of Power Game}

Through the process of the game between the government and the market, we can fully understand that the consequences of the game have caused the failure of both the government and the market. Market failure means that no matter what market economy system can no longer run effectively after being laissez faire. The government can effectively restrain the individual's economy from the public interest and avoid the excessive pursuit of individual interests. Under the relative comparison, the government can be more appropriate than the market to control the public interest and more smoothly manage the main activities of the society. But the government also has government failure. Sometimes, because the market does not intervene excessively, it will cause the loss of public interest which the government cannot imagine. Market failure and government failure are common knowledge of modern economics and a basic phenomenon. Therefore, the government must understand the essence and starting point of public management in the future public management, and the pursuit of public interest can be better for public management. After analyzing the consequences of the game, we can see that the public rationalism and public interest of the market and the government are being forgotten by people.

\section{Significance of Power Game between Government and Market to Public Interests Return}

\subsection{Power Game between Government and Market in the Process of Urbanization}

Through the game of government and market power in the process of urbanization to investigate the return of public interest, the government and market system need to participate in the economic game. Through the model hypothesis, the game of public interest can be better understood. In the process of urbanization, the main data of the market and the government are assumed, and the significance of the game is analyzed by the formula. If the interference force is $\mathrm{L}$, the interference of the government to interfere with the economy is $\mathrm{P}$, then $\mathrm{L}$ is an increasing function of the $\mathrm{P}$, in other words, the government's interference with the economy increases with the increase of interference. Increase. Assuming that the government I takes non interfering measures in $A=0$, the government takes interference measures at $A=1$; the revenue of government $I$ in the nonintervention economy is $\mathrm{Wj}$, and the income of 1-P is $\mathrm{W}_{\mathrm{j}}+\mathrm{R}(\theta)$ when it interferes in the economy but does not interfere with the economy (1-P), and the income of $\mathrm{P}$ is $\mathrm{W}_{\mathrm{j}}-\mathrm{F}$. and $\mathrm{Wj}$ is the moderate intervention economy of government I. $R(\theta)$ is the additional revenue that the government I moderately intervenes in the economy. $\mathrm{F}$ is the loss of revenue caused by excessive government intervention. 
Through the analysis of data, we can conclude that the expected revenue of government $i$ when intervening is:

$$
\mathrm{P}\left(\mathrm{W}_{\mathrm{j}}-\mathrm{F}\right)+(1-\mathrm{P}) \cdot\left[\mathrm{W}_{\mathrm{j}}+\mathrm{R}(\theta)\right]
$$

When the government $\mathrm{i}$ takes the expected revenue of $\mathrm{W}_{\mathrm{j}}$. when it is unwilling to go to the economy, the conditions for the government I to intervene in economic activities are:

We have:

$$
\mathrm{P}\left(\mathrm{W}_{\mathrm{j}}-\mathrm{F}\right)+(1-\mathrm{P}) \cdot\left[\mathrm{W}_{\mathrm{j}}+\mathrm{R}(\theta)\right] \geqslant \mathrm{W}_{\mathrm{j}}
$$

$$
\mathrm{W}_{\mathrm{j}} \leqslant \mathrm{W}_{\mathrm{j}}+\mathrm{R}(\theta)-\mathrm{PF} / 1-\mathrm{P} \text {. }
$$

From the above analysis, we can understand that when $\mathrm{W}_{\mathrm{j}}$ is certain, by reducing the probability of interfering the economy by government intervention $\mathrm{P}$, the reduction of $\mathrm{P}$ is also reduced by the government's dry perforce L. Reducing the intensity of government interference will greatly promote the urbanization and economic development in China. The failure of the government may lead to greater loss efficiency than loss of market failure, which requires the government to make appropriate concessions to the market. Only in this way can the public interest be maximized from the game of power game between the government and the market.

\subsection{Power Game between Government and Market in the Supervision of Internet Information.}

The power game between government and market in the process of urbanization can also make a better effect on the analysis of the power game between the government and the market in the Internet information supervision. First, we also need to build the game model and set up the main data in the game to further analyze and solve the problem.

If the income is $\pi$, the additional revenue that provides violation information is $\pi_{\omega}$, the Internet industry and social benefit is $\mathrm{V}$, the additional loss of the illegal information is $\mathrm{V}_{\omega}$. The internal review needs to pay the regulatory $\operatorname{cost} C_{r}$, the regulatory activities need to pay the cost of $C_{g}$, and the probabilities of $\alpha$ when providing illegal information are found by the regulatory authorities. Therefore, the income of the loss is alpha, the government regulators reduce the economic and social losses to $\alpha \mathrm{V}_{\omega}$, and the cost of obtaining a fine is $\alpha \mathrm{V}$, and $\alpha$ can also be the level of government efforts. With the increase of government supervision efforts, the probability of internet information regulation has been increased and the cost of government regulation is increasing. Secondly, $\beta$ is an excessive regulatory sensitive group and no excessive monitoring sensitive population, and $0 \leq \beta \leq 1$, $0 \leq \gamma \leq 1, \gamma \neq 1-\beta$. The enterprise will face the loss of $\beta \pi$, the government is faced with the loss of the income of $\beta \mathrm{V}$. In the negative regulatory strategy, enterprises face the loss of income from $\gamma \pi$, and the

\begin{tabular}{|c|c|c|c|}
\hline & Game players & Governme & ators (Player 2) \\
\hline & & Active supervision & Negative supervision \\
\hline & Active & $\pi-C_{r}-\beta \pi, \quad V$ & $\pi-C_{r}-\beta \pi, \quad V-\gamma V$ \\
\hline & self-examination & $-C_{g}-\beta V$ & \\
\hline 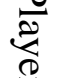 & Negative & $\pi+\pi_{\omega}-\gamma \pi$ & $\pi+\pi_{\omega}-\gamma \pi, \quad \mathrm{V}-\mathrm{V}_{\omega}$ \\
\hline$\bullet$ & self-examination & & $-\gamma \mathrm{V}$ \\
\hline
\end{tabular}
social loss of government $\gamma \mathrm{V}$.

For the above assumptions, we can analyze and answer questions more vividly in form.

Through the analysis of the table, it is assumed that the positive self-examination probability of the game party 1 is $\mathrm{p}$, the $1 \mathrm{p}$ is a negative self-examination probability, the positive self-examination probability of the second game party is q, and the 1-q is the negative supervision probability, and the conclusion is concluded.

$$
\begin{aligned}
& \mathrm{P}\left(-\mathrm{C}_{\mathrm{g}}-\beta \mathrm{V}\right)+(1-\mathrm{p})\left(\alpha \mathrm{V}_{\omega}+\alpha \mathrm{V}-\mathrm{V} \omega-\mathrm{C}_{\mathrm{g}}-\beta \mathrm{V}\right)=\mathrm{p}(-\gamma \mathrm{V})+(1-\mathrm{p})-\left(\mathrm{V}_{\omega}-\gamma \mathrm{V}\right) \\
& \mathrm{q}\left(-\mathrm{C}_{\mathrm{r}}-\beta \pi\right)+(1-\mathrm{q})(-\mathrm{Cr}-\beta \pi)=\mathrm{q}\left(\pi_{\omega}-\alpha \pi-\gamma \pi\right)+(1-\mathrm{q})\left(\pi_{\omega}-\gamma \pi\right)
\end{aligned}
$$


Therefore, $\mathrm{P}=1-\mathrm{C}_{\mathrm{g}}-(\gamma-\beta) \pi / \alpha\left(\mathrm{V}+\mathrm{V}_{\omega}\right), \mathrm{q}=\pi_{\omega}+\mathrm{C}_{\mathrm{r}}-(\gamma-\beta) \pi / \alpha \pi$.

From the game analysis of the power of the government and the market in the internet information supervision, the government can give the government a proper concession to the market, so that the public interest can be maximized from the power game of the government and the market.

\subsection{Civil Society, Governance and Good Governance Theory}

Through relevant data, we can understand that effective governance will promote the public interest of the government and the market. Based on governance theory, the theory of civil society once again prevails. The fundamental purpose of this idea is to maintain the public interest and ultimately make citizens one of the main rights holders of society. The good governance is based on the citizen, is a new social governance model which is different from the other traditional social management methods. It is a kind of innovation which is the derivative of the governance theory and refers to the main process of maximizing the public interest. The essence of good governance is to realize the common control of government and citizens on social life. Unlike previous theories, it is a new form of relationship between a political country and a citizen. The study of such problems shows that civil society, governance and kindness have been fundamentally different from the previous theories. It has already returned to the public interest of public management from a certain extent to the debate on public rationalism.

\subsection{Consequence Analysis of Power Game between Government and Market}

The game between government and market rights is a game of public interest. The theory school of public choice, represented by James Buchanan and Gordon Tarlock, believes that there will be some negative reasons in the market, which leads to the lag of its existence and the market failure in serious words. The government will also produce a failure phenomenon, and the failure of the government will have a serious negative impact. Through the understanding of the basic national conditions of our country, if the phenomenon of government failure has occurred in China, it will have a great influence on the development of our country, which will not only impede the development of our country, but also affect the living standard of our people. It is conceivable how terrible the government failure is to a country. One thing, in view of the game between the rights of the government and the market, must have a favorable impact on the living standard of the people. Only based on guaranteeing the living standard of the people can we carry on the game of power.

\section{Main Relations between Government Power and Public Interests}

Through learning, we realize that the rational maximization of the government's rights is the guarantee for the realization of a good social development, and the reasonable ownership is the basis for the realization of the public interests. Once Jacques Russo's social theory system has proved that the legitimacy of the government's rights is the basis for the realization of the maximization of public interests. Yes. The value of government lies in the development of people and the state. Its main responsibility is to strive for maximizing public interests. And Rousseau said, "if one day the existence of the government is not to fulfill the obligations of the citizens, then the government can be abolished, and a new institution can be set up, and it can serve the public interest wholeheartedly." Through the understanding of the question of appeal, it is not difficult to find that the public interest of the government's rights has a distinct attribute, because the government is an institution that exists for the public interest, and it is for public management. The goal of the government to maximize the public interest is not only to prove that the existence of the government is meaningful, but to a certain extent it is a major moral obligation. In fact, the government and the market are working for the progress of the people, although they have a game in the rights, but only through appropriate means to distribute the work, the public interest will be mentioned a relatively high standard. 


\section{Conclusions}

Based on the analysis of the game of power between the government and the market, we can see that we must proceed from the actual situation. In the face of problems related to the government and the market, we must recombing the subordination of public interests in public administration. We should recognize the "good" brought about by the new mode of social management in public administration. When the needle is facing the problems faced by the government and the market, our country must start from the fundamental national conditions, and in the future social progress, we should take the government's public management as the legal basis and maximize the public interests through effective means to promote the harmonious development of the society.

\section{References}

[1] Wang Huiyong. A new View Point on Common Interests in Public Management [J]. Journal of Dongguan University of Technology, 2006, 13(2): 1-4+15.

[2] Li Jianhua, Niu Lei. Chief Reports:Loyalty to a New Administration - Interpretation of the Plight of the Chief Ethics Pledge [J]. Journal of Nanchang University (Humanities and Social Sciences), 2007, 38(1): 70-73.

[3] Yu Dandan. Analysis of the Game Relation between Government Intervention and Market Competition - Taking the Merge of DiDi and Uber as an Example [J]. Innovation Science and Technology, 2017, 204(2): 73-75.

[4] Wang Heyi, Wang Yibao. Research on the Cause and Regulation of Supply Side Reform Based on the Game Relationship between Government and Market [J]. China Soft Science, 2018(3): 76-85. 